\title{
A imagem corporal nas açôes educativas em autocuidado para pessoas que tiveram hanseníase
}

I ${ }^{1}$ Talitha Vieira Gonçalves Batista, ${ }^{2}$ Carmen Silvia de Campos Almeida Vieira, ${ }^{3}$ Maria Angela Boccara de Paula I

Resumo: Os comprometimentos físicos ocasionados pela hanseníase são pactuados nas ações do Plano Nacional de Controle da Hanseníase e são considerados um grave problema de saúde pública. Como forma de prevenir o avanço de incapacidades, o Ministério da Saúde propõe ações educativas em autocuidado. No entanto, apesar da enfática importância da realização do autocuidado, observa-se a não aderência dos pacientes ao programa, que pode ser justificada, dentre outros motivos, pela desestruturação de sua imagem corporal e pelo estigma advindo das representações sociais do corpo "leproso". Sendo assim, acredita-se na importância de ampliar o discurso tecnicista nas ações educativas em autocuidado, considerando a imagem corporal como aspecto importante nas estratégias de tratamento da doença. Objetiva-se conhecer a imagem corporal de pessoas que tiveram hanseníase e que desenvolveram incapacidades físicas. Para tanto, aplicou-se o teste psicológico Desenho da Figura Humana (DFH), com ênfase na análise interpretativa das mãos e dos pés, locais mais afetados pela hanseníase, em cinco mulheres cadastradas e em acompanhamento no Programa de Autocuidado em Hanseníase de um Ambulatório Regional de Especialidades de um município do Vale do Paraíba Paulista. O teste foi realizado no período de março a dezembro de 2009. Os resultados revelaram a não inclusão ou a desfiguração de mãos e pés. Existe uma falta de integração dessas regiōes à consciência, acarretando desestruturação da imagem corporal, que pode decorrer tanto da perda de sensibilidade cutânea como da deformidade advindas da doença. Infere-se que essa desestruturação da imagem corporal dificulta a aderência ao autocuidado e a sociabilização dessas pessoas, aumentando o estigma da hanseníase.

> Palavras-chave: hanseníase; imagem corporal; representação social do corpo; desenho da figura humana.
1 Psicóloga; mestranda em Desenvolvimento Humano: Formação, Políticas e Práticas Sociais pela Universidade de Taubaté. São Paulo, Brasil. Endereço eletrônico: talitha. vgb@gmail.com

2 Enfermeira; doutoranda em Enfermagem pela UNICAMP; professora da Universidade de Taubaté. São Paulo, Brasil. Endereço eletrônico: carmenn vieira@outlook.com.

${ }^{3}$ Enfermeira. Doutora em Enfermagem pela USP; professora da Universidade de Taubaté. São Paulo, Brasil. Endereço eletrônico: boccaradepaula@hotmail.com. 


\section{Introdução}

O Brasil ocupa hoje o segundo lugar mundial em número de casos de hanseníase, atrás somente da Índia. O Programa Nacional de Hanseníase, por meio do Plano de Eliminação (PEL), tem “[...] como meta a eliminação da hanseníase enquanto problema de saúde pública, isto é, atingir prevalência de menos de um caso por cada dez mil habitantes [...]” (BRASIL, 2006, p. 10). Dados recentes mostram redução da taxa de prevalência da doença, porém a meta de eliminação para o país ainda não foi atingida (CASOS..., 2012).

Causada pelo Mycobacterium leprae, a hanseníase é uma doença crônica, cuja manifestação ocorre em células cutâneas e nervos periféricos. Tendo como característica principal o comprometimento dos nervos, quando não devidamente tratada, a hanseníase pode ocasionar o aparecimento de incapacidades físicas irreversíveis, que podem evoluir para deformidades. Esse quadro resulta num grande sofrimento, que ultrapassa a dor, pois, vinculados ao prejuízo físico, inserem-se nele os impactos psíquico e sociocultural (BAIALARDI, 2007).

Vale ressaltar que as incapacidades são classificadas, de acordo com o Ministério da Saúde, nos graus I e II. O grau I refere-se à perda da sensibilidade protetora, tanto dos olhos como dos membros superiores e inferiores. $\mathrm{O}$ portador de hanseníase de grau II pode apresentar lagoftalmo e/ou ectrópio, triquíase, opacidade corneana central, acuidade visual menor que 0,1 ou incapacidade de contar dedos a $6 \mathrm{~m}$. Na mão, pode apresentar lesóes tróficas ou traumáticas, garras, reabsorção ou mão caída. Nos pés, pode apresentar igualmente lesões tróficas ou traumáticas, garras, reabsorção e também pé caído e contraturas do tornozelo (BRASIL, 2008).

As incapacidades e deformidades físicas interferem na imagem corporal da pessoa, gerando preconceitos, discriminações e exclusões sociais. Como forma de prevenir o avanço de incapacidades já instaladas e de futuras incapacidades e deformidades, o Ministério da Saúde (MS), por meio do Programa de Controle da Hanseníase, propõe ações educativas em autocuidado, por meio de três manuais: "Autocuidado em hanseníase: face, mãos e pés" (para usuários), "Eu me cuido e vivo melhor" (caderno de monitoramento do autocuidado para usuários) e "Guia de apoio para grupos de autocuidado em hanseníase" (para profissionais de saúde e usuários capacitados para atuar como coordenadores de grupos). No 
que diz respeito aos usuários, as estratégias de prevenção incluem uma série de cuidados técnicos e exercícios com enfoque na face - em especial nos olhos e no nariz -, nas mãos e nos pés, locais mais afetados pela hanseníase (BRASIL, 2010). Observa-se, portanto, que essas ações preventivas em autocuidado são pautadas exclusivamente na dimensão física do corpo, por meio de técnicas criteriosamente pré-definidas, o que mostra uma abordagem de intervenção tecnicista.

Como psicóloga voluntária de um Programa de Hanseníase de um Ambulatório Regional de Especialidades de um município do Vale do Paraíba Paulista, pude observar, em minha prática profissional, dificuldades dos pacientes em aderir ao autocuidado. Infere-se que esse fato decorra, dentre outros motivos, da desestruturação da imagem corporal e do estigma advindos das representações sociais do corpo "leproso", incapacitado e deformado.

Essas considerações remetem ao seguinte questionamento: as representações da pessoa acerca do próprio corpo estruturam as práticas em autocuidado ou as práticas são determinadas pelas representações? Se as práticas em autocuidado não são uma expressão final das representações do corpo, mas estas são uma condição para aquelas, torna-se necessário indagar quais elementos influenciam, determinam ou condicionam as ações e os modelos de pensamento do paciente com hanseníase.

Considerando que o autocuidado é essencial para minimizar ou prevenir consequências da hanseníase e que a aderência às orientações com o cuidado do próprio corpo demanda, além da informação, a internalização de conceitos que possam favorecer a compreensão das possíveis alterações na imagem corporal que a hanseníase pode causar, este estudo teve como objetivo conhecer a imagem corporal formada por pessoas que tiveram hanseníase e que desenvolveram deformidades físicas.

Acredita-se que por meio desse conhecimento se possa auxiliar o indivíduo no reconhecimento de sua dor, de suas angústias, esperanças e perspectivas e, assim, agregar novos conceitos às ações educativas em autocuidado para a pessoa que teve hanseníase. Espera-se que estes novos conhecimentos favoreçam à equipe de saúde um olhar integral do indivíduo com hanseníase, ao preocupar-se não apenas com o cuidar/educar técnico, mas, acima de tudo, com as dimensões psíquicas e socioculturais do cuidado na hanseníase. 


\section{Materiais e métodos}

Trata-se de estudo descritivo, de abordagem qualitativa, com o objetivo de conhecer a imagem corporal de pessoas com deformidades físicas decorrentes da hanseníase. Antes de se iniciar a coleta dos dados, o projeto foi aprovado pelo Comitê de Ética em Pesquisa em Seres Humanos da Universidade de Taubaté (CEP/Unitau) sob o no 417/09, conforme Resolução no 196 de 10 de outubro de 1996, vigente à época da realização da pesquisa.

Como instrumento para coleta dos dados, utilizou-se o teste psicológico Desenho da Figura Humana (DFH), com ênfase na análise interpretativa das mãos e dos pés, locais mais afetados pela hanseníase. Optou-se pelo $\mathrm{DFH}$, pois este consiste em uma técnica projetiva gráfica, cujo objetivo é conhecer a imagem corporal, a partir do desenho do corpo. Para desenhar a "figura", o indivíduo busca imagens internas que faz de si mesmo e dos outros. A figura retratada é, frequentemente, uma combinação dessas imagens, produto das experiências, identificações, projeções e introjeçôes que constituem a personalidade (MACHOVER, 1967).

Para a aplicação do teste, foram oferecidos folha de papel sulfite na posição vertical, lápis preto no 2 e borracha. As instruçōes foram as seguintes: "Desenhe, por favor, uma pessoa inteira. Você poderá fazer como quiser, só não pode ser desenho de palitinhos". Em caso de perguntas, respondeu-se apenas: "Como você quiser". Vale salientar que o teste foi aplicado conjuntamente, em uma das reuniōes de autocuidado promovidas pelo Programa de Autocuidado em Hanseníase de um Ambulatório Regional de Especialidades de um município do Vale do Paraíba Paulista, em 2009.

Participaram do estudo cinco mulheres cadastradas e em acompanhamento ativo no referido programa. Os critérios de seleção da amostra foram: pessoas com alta por cura da hanseníase; pessoas com incapacidade física Grau II, de acordo com a avaliação do grau de incapacidade proposta no Manual de Prevenção de Incapacidades do Ministério de Saúde; pessoas que participaram ativamente do grupo de autocuidado, proposto mensalmente pelo programa de autocuidado.

Os dados foram analisados qualitativamente, por meio da interpretação do DFH proposta por Machover, adaptada com base nas proposiçōes de Van Kolck (1984). Baseando-se nas considerações e interpretaçôes realizadas por Machover sobre o DFH, Van Kolck (1984) elaborou, no Brasil, um protocolo de avaliação 
e interpretação do DFH composto por três categorias analíticas: aspectos gerais,

formais e conteúdo dos desenhos. No entanto, neste estudo, consideraram-se para a interpretação do DFH dois itens relacionados aos aspectos do conteúdo do desenho, mãos e pés, por serem as regiões do corpo mais afetadas pela hanseníase e onde surgem frequentemente as incapacidades e deformidades físicas.

Acredita-se que a análise do DFH pode ser uma ferramenta eficaz para se conhecer a imagem corporal e as representações sobre o corpo de pessoas que tiveram a doença e desenvolveram deformidades físicas.

\section{Resultados}

A análise das produções gráficas revelou a não inclusão ou a desfiguração de mãos e pés pelas pessoas. Em relação às mãos, dois desenhos as tiveram rasuradas e um desenho as omitiu. A mão, simbolicamente, representa o contato interpessoal. Portanto, a negação das mãos nos leva a inferir dificuldades das pessoas no contato social. Em relação aos pés, quatro dos cinco desenhos tiveram os pés rasurados ou pintados de preto. Os pés simbolizam a base. Rasurados, podem representar uma insegurança em relação ao meio. Essa hipótese se intensifica pelo fato de muitos dos desenhos estarem "flutuando", sem chão.

A não inclusão, ou a desfiguração, das mãos e dos pés mostra que essas são regiões conflitantes, que não se encontram integradas à consciência, o que acarreta desestruturação da imagem corporal. A não aceitação ou negação dessas partes do corpo pode decorrer da perda de sensibilidade cutânea e da deformidade advindas da doença.

Outra questão observada por meio das figuras é que esses indivíduos têm dificuldades no contato interpessoal e no "estar no mundo", que podem ser justificadas, portanto, pelo estigma decorrente da hanseníase.

Destaca-se, ainda, que a desestruturação da imagem corporal dificulta que as ações em autocuidado sejam realizadas de forma efetiva. Diante disso, acredita-se que, para que as pessoas acometidas pela hanseníase tenham maior aderência ao autocuidado, seja necessário repensar as ações educativas em saúde preconizadas pelo Ministério da Saúde, ancoradas na Biomedicina, incluindo os sentidos e os significados, isto é, as representações sociais dos pacientes em relação à doença e a seus corpos modificados por ela, de modo a empoderá-los de um autocuidado mais efetivo e consciente. 


\section{Discussão}

Os resultados mostraram que tanto os pés como as mãos são regiōes que representam conflitos (VAN KOLCK, 1984), isto é, falta integração dessas regiões à consciência, o que acarreta desestruturação da imagem corporal, que pode decorrer da perda de sensibilidade cutânea e da deformidade advindas da doença.

A mão, simbolicamente, representa o contato interpessoal, as defesas do ego em relação ao ambiente (VAN KOLCK, 1984). As mãos rasuradas ou omitidas nos levam a inferir dificuldades no contato social, dificuldades em se adaptar socialmente, gerando insegurança na relação com o meio externo.

Os pés simbolizam a base, o "enraizamento". Os pés desfigurados, rasurados e pintados de preto, podem representar uma dificuldade em colocar-se e dominar o seu espaço em seu meio, uma insegurança "no caminhar". Essa hipótese se intensifica pelo fato dos desenhos estarem "soltos ao papel", sem chão, sem raiz. Vale salientar que, de acordo com Leloup (1998), o equilíbrio do corpo, do psiquismo e da vida espiritual depende, de certa maneira, desse enraizamento. Se as raízes são sadias, toda a árvore é sadia. "Algumas vezes somos jardineiros, muito atentos à flor e ao fruto, mas se esquecemos as raízes, esquecemos os pés. E, portanto, é por lá talvez que deveremos começar os nossos cuidados” (LELOUP, 1998, p. 34).

A não inclusão, ou desfiguração, das mãos e dos pés mostra que estas são regiões conflitantes e, portanto, não se integraram à consciência. A não integração dessas partes do corpo à consciência pode decorrer da perda de sensibilidade cutânea e da deformidade advindas da doença, o que reitera a estigmatização.

O estigma sofrido pela pessoa acometida pela hanseníase (ou lepra) é milenar. Mesmo após a descoberta da sua cura, as raízes de suas representações sociais ainda são resistentes, pois sua imagem ainda se encontra associada a deformidades físicas, gerando medo e repulsa nas pessoas em geral, o que favorece a exclusão social.

Diante desse contexto, verifica-se que os mecanismos excludentes que a lepra suscitou reforçam a forma de estruturação social, que precisava isolar e controlar os seus elementos perturbadores para se afirmar como dominante. Dessa forma, a segregação e o confinamento que se cristalizaram em torno dos "leprosos" vão permanecer por muito tempo no tratamento que a sociedade ocidental dispensará aos seus excluídos (FOUCAULT, 2002; PINTO, 1995). 
O estudo de Borenstein et al. (2008), ao narrar a história de vida de três expacientes de hanseníase internados na Colônia Santa Teresa (SC), demonstrou o estigma e a exclusão nos variados espaços e situações, desde núcleos familiares até o espaço interno institucional.

Como verificado nos desenhos das mulheres deste estudo, o medo da exclusão social pode estar explicitado na ocultação das regiōes do corpo que denunciam a hanseníase. Pode-se dizer, ainda, que a dificuldade de socialização é causada pela desestruturação da imagem corporal, pois existe "um intercâmbio contínuo entre nossa própria imagem e a dos outros" (SCHILDER, 1994, p. 240). Tavares (2003) afirma que a imagem corporal relaciona-se ao sentido das imagens corporais que circulam na sociedade. Isto remete à afirmação de que em qualquer meio sempre existirá uma imagem social do corpo, isto é, um símbolo que os indivíduos rejeitam ou por meio do qual se identificam. Na hanseníase, o estigma encontra-se diretamente relacionado ao corpo, e é sobre ele que recai a maior parte das representações sociais. Mas que corpo é esse de que estamos falando?

Ao longo dos tempos, o corpo revela sua história, que pode se apresentar de variadas formas, dependendo do contexto sociocultural no qual está inserido (LE BRETON, 2006). As representações sociais do corpo têm sido concebidas durante muitos anos seguindo uma tradição dualista e hierárquica que vem de Platão e se expressa em Descartes por meio da dicotomia corpo-mente. Na Idade Clássica, o corpo humano foi tratado por Platão como algo desprovido de inteligência, sede de paixões desnecessárias, isto é, o corpo era tido como prisão da alma. No período medieval, o forte domínio da Igreja Católica influenciou a visão de corpo como fonte de pecado. $\mathrm{Na}$ Idade Moderna, com o positivismo e o empirismo, estabeleceu-se o cogito como entidade separada do corpo, consagrando-se, assim, a dicotomia mente-corpo presente na ciência moderna (SILVA, 1999).

Para Foucault (2007), o surgimento do corpo como objeto científico é um dos representantes das implicações do capitalismo na percepção de como os indivíduos veem a si próprios e são vistos pela sociedade. Portanto, a mudança do feudalismo, um sistema socioeconômico e cultural baseado em valores arraigados na religiosidade, para o capitalismo, com suas práticas e valores assentados na racionalização, possibilitou uma nova forma de se perceber o corpo, pautada em novos valores e novas ideologias (CAVALCANTI, 2005). Assim, se antes o controle disciplinar se dava por meio de aparelhos repressivos, 
a partir do capitalismo ele ocorre via hedonismo, pela liberalização da sedução, da sexualidade e do prazer como uma nova forma de investimento e tentativa de controle do corpo (CAVALCANTI, 2005; FERREIRA, 2008). Segundo Foucault (2007, p.147), “como resposta à revolta ao corpo, encontramos um novo investimento que não tem mais a forma de controle-repressão, mas de controleestimulação: fique nu... mas seja magro, bonito, bronzeado!”.

A preocupação com o belo foi se fortalecendo ao longo do século XX. Hoje, a contemporaneidade pauta-se em um ideal de corpo perfeito, forte, bonito, jovem, produtivo e saudável, o que favorece um culto ao corpo idealizado que fomenta uma consciência corporal cada vez mais narcisista (SANTAELLA, 2004). Nesse contexto, os que fogem à norma estabelecida historicamente e não compartilham dos atributos de corpo ideal nomeiam-se e são nomeados “diferentes” (LE BRETON, 2006), fato que contribui ainda mais para cristalizar uma representação social negativa do corpo da pessoa com hanseníase.

Constata-se, portanto, que o corpo deformado pela hanseníase tem significados construídos socialmente em um processo dinâmico, determinado por condiçôes históricas e socioculturais (LANGDON, 1995). Em uma sociedade capitalista e tecnocrata, a representação do "diferente" ou "desviante" torna-se intolerável, pois o corpo "leproso" e "deformado" afasta-se dos atributos de produtividade (corpo-máquina), bem como dos padrões estéticos de beleza, consumo e prazer (corpo-objeto), suscitando nos doentes sentimentos de inadequação e provocando discriminação por parte dos outros. Esse fato configura o estigma associado ao corpo deformado (SANTOS; SAWAIA, 2000).

De acordo com as autoras, as concepções sobre as imagens valorizadas e desvalorizadas socialmente nos levam a considerações importantes: a imagem corporal é um dos componentes fundamentais da identidade; a representação social, como forma de conhecimento prático, é estabelecida pelo sujeito social com atividade simbólica e cognitiva, que ressignifica, transforma e constrói novos conhecimentos; as representaçôes sociais do corpo ideal, ancoradas na sociedade capitalista, pautam-se nos atributos de beleza, jovialidade, magreza e saúde.

Verificou-se, por meio dos desenhos, que as mulheres atribuíam a felicidade a sua aparência física. Então as manchas, as feridas, os pelotes e a pele escurecida são sinônimos de infelicidade. Isso porque, para a mulher, a beleza está associada a um dever sociocultural: ser bela é estar em conformidade com os padrões de 
beleza estabelecidos na e pela sociedade (SILVEIRA, 2012). Se considerada a imagem que as mulheres constroem continuamente sobre si (a partir do julgamento do outro), é possível perceber o quanto lhes é insatisfatório viver em um corpo cujos padrōes encontram-se distantes do ideal aceito socialmente.

Essas questôes permitem observar a função de orientação das representações sociais, isto é, no imaginário social existe um padrão ideal que determina comportamentos e práticas, mas também determina as necessidades e anseios dos sujeitos no que diz respeito ao seu próprio corpo.

Nesse sentido, questiona-se: se a identidade é constituída dialeticamente pela definição de si mesmo do outro, quais estratégias essas mulheres utilizam para manter a integridade de suas identidades? Pode-se inferir que seja por meio do acobertamento do corpo, no sentido de esconder os sinais deixados pela doença, como uma forma de evitar a exposição do corpo que demonstra o estereótipo causador do estigma. Verifica-se esse fato pelas rasuras e/ou ocultamento dos pés e das mãos nos desenhos. Da mesma forma, nos estudos realizados por Baialardi (2007), Eidt (2004) e Claro (1995), observou-se que as pessoas acometidas pela hanseníase demonstraram sentimentos de vergonha e medo de expor seu corpo, em virtude das deformidades deixadas pela doença, como manchas e cicatrizes provenientes das lesões de pele. Silva e Silva (2002) também afirmaram que alterações da imagem corporal podem desencadear sentimentos negativos de inferioridade, complexos e insegurança nos indivíduos que as vivenciam. Em decorrência do sentimento de inadequação, tentam esconder as marcas de seus corpos.

O estigma associado à hanseníase permanece no imaginário social, remetendo os indivíduos aos tabus da morte e da mutilação e trazendo grande sofrimento psíquico aos seus portadores, com sérias repercussões em sua vida pessoal. O estigma se efetiva a partir do isolamento social que envolveu a doença, evidenciado na atualidade por meio de atitudes excludentes vivenciadas pelos indivíduos doentes, que preferem ocultar seu corpo, na tentativa de esconder a doença e, assim, evitar a rejeição (EIDT, 2004). Entretanto, esses comportamentos estabelecem um círculo vicioso, pois acobertar a doença sugere a realização tardia do diagnóstico e, consequentemente, o aumento da possibilidade de sequelas.

O fato das mulheres deste estudo apresentarem incapacidades físicas de grau II e a maioria ter sido diagnosticada pela forma virchowiana da doença - advinda 
da hanseníase indeterminada (HI), considerada a primeira manifestação clínica da hanseníase e não contagiante - pode sugerir uma ineficácia do autocuidado. Em estudo realizado por Macário (2002), foi constatado que pacientes afetados pela hanseníase apresentam perda da sensibilidade protetora nas mãos e nos pés, e seus desenhos apresentam-se incompletos em $68,75 \%$ dos casos.

Como forma de prevenir as deformidades, tem-se o autocuidado, que pode ser compreendido como um modelo conceitual que exige atitude "racional com tomada de decisão para realizar ações antecipatórias e oportunas, que busquem a responsabilidade do cuidado individual, que se traduz em ações sistematizadas, coordenadas e integradas pelo indivíduo em seu cotidiano" (CHOMPRÉ, 1994, p.155). No entanto, no atual sistema de saúde, a capacidade do indivíduo para participar do cuidado com seu próprio corpo é reduzida ou anulada. Mesmo em situações nas quais o indivíduo é quem deve ser o responsável pelo seu cuidado, as orientações e recomendações que não são seguidas representam um comportamento de resistência, o que leva a equipe de saúde ao julgamento de não aderência ao programa. Nesse sentido, questiona-se: a não aderência ao autocuidado é responsabilidade exclusiva dos indivíduos acometidos pela hanseníase ou se poderia dizer que é também uma responsabilidade de um paradigma do cuidar que transforma o indivíduo em objeto passivo no cuidado com o seu próprio corpo?

Vários trabalhos apontam para a fragilidade do sistema de saúde atual e propõem mudanças no modo de assistir o indivíduo (VASCONCELOS, 1989; MAIA, 1991; ARAÚJO, 1991). Entre os fatores que permitem reconhecer o processo de tomada de decisão para o autocuidado, destaca-se a importância de democratizar os conhecimentos, de dispor tecnologias adequadas, de conhecer o imaginário sociocultural da doença em questão, bem como as percepçôes do processo saúde/doença e as motivaçóes para o cuidado com o próprio corpo (CHOMPRÉ, 1994).

Portanto, a possível falta de aderência ao autocuidado nos remeteu ao seguinte questionamento: as representaçōes das mulheres do próprio corpo estruturam as práticas de autocuidado ou estas são determinadas pelas representações do corpo? Infere-se que as representaçōes sociais estruturam as práticas de autocuidado e, dialeticamente, estas estruturam aquelas. Isto é, as representações sociais ligadas ao 
corpo deformado, incapacitado e insensível propiciam um autocuidado ineficaz,

assim como o autocuidado ineficaz aumenta as incapacidades e deformidades, em um ciclo constante.

Diante disso, acredita-se que, para que as pessoas acometidas pela hanseníase tenham maior aderência ao autocuidado, faz-se necessário repensar as ações educativas em saúde preconizadas pelo Ministério da Saúde, ancoradas na Biomedicina, incluindo os sentidos e os significados, isto é, as representações sociais dos pacientes em relação à doença e a seus corpos modificados pela hanseníase, de modo a empoderá-los a um autocuidado mais efetivo e consciente. Assim, incluir nas ações educativas em autocuidado as representações sociais sobre uma doença crônica, como a hanseníase, requer compreender não apenas informaçōes sobre as concepções coletivas do que representa estar doente, mas, também, como esses processos foram construídos e reelaborados à luz das experiências pessoais e compartilhadas (HERZLICH, 2005).

O processo de adoecer de hanseníase tem um significado específico para o doente, construído a partir de vivências individuais e do convívio com a doença. O espaço que a doença ocupa na vida e no corpo da pessoa doente depende desse significado, que é único, pois sofre influências internas, com base na história individual, e externas, baseadas nas representações da doença. Dessa forma, as pessoas têm representaçôes, tanto da sua doença como do seu adoecer, que independem do saber médico, pois o significado da doença e do adoecimento depende do sentido que se atribui a eles (ADAM; HERZLICH, 2001).

De acordo com Tronca (2000), estudar a hanseníase é também contribuir para se retirar a doença de um relativo esquecimento ou desmerecimento por parte da historiografia científica e cultural. Para o autor, a hanseníase merece ser analisada não apenas por ser uma doença cujas representações sociais, que remontam à Antiguidade, ainda permanecem no imaginário social, mas também porque se acredita que talvez a explicação para o vigor com que o estigma ainda sobreviva na atualidade esteja no descaso dispensado à doença. Isso porque em todos os lugares e a cada época é o indivíduo que é doente, mas ele é doente aos olhos da sua sociedade, em função dela, e segundo as modalidades que ela fixa. O discurso do doente se elabora, portanto, no interior do próprio discurso das relações do indivíduo com o social. 


\section{Conclusão}

O "estar doente" de hanseníase remete a desestruturações físicas, psíquicas e socioculturais, causadas, principalmente, pelas incapacidades e deformidades físicas, pelo estigma, preconceitos, discriminações, exclusões e desestruturações da imagem corporal, que podem interferir na aderência ao autocuidado.

Observou-se nas mulheres deste estudo uma desestruturação da imagem corporal, isto é, uma falta de integração à consciência de partes do corpo como mãos e pés, a qual pode decorrer tanto da perda de sensibilidade cutânea como da deformidade advindas da hanseníase.

A desestruturação da imagem corporal pode dificultar o relacionamento interpessoal e o "estar no mundo" dessas pessoas, aumentando o estigma característico da doença. Além disso, ela impede que o autocuidado com o próprio corpo seja realizado com consciência corporal e, consequentemente, com dimensão da sua importância.

Acredita-se que agregar novos conceitos sobre o corpo nas ações educativas do autocuidado pode contribuir na aderência do paciente com hanseníase ao cuidado do próprio corpo, favorecendo um processo de consciência corporal, ao empoderálo na redescoberta de sua imagem corporal, visando o entendimento de suas peculiaridades e contribuindo na construção de uma identidade corporal própria.

Conclui-se que o DFH se mostrou adequado frente ao objetivo proposto, pois possibilitou a projeção de conteúdos internos que vão além da consciência e que exercem papel determinante na constituição da imagem corporal. No entanto, salienta-se a necessidade de se realizar mais pesquisas sobre a temática, ampliando o debate sobre a possibilidade de se incluir a imagem corporal nas ações educativas em autocuidado para pessoas que tiveram hanseníase. ${ }^{1}$

\section{Referências}

ADAM, P.; HERZLICH, C. Sociologia da doença e da medicina. Bauru: Edusc, 2001.

ARAÚJO, M. J. S. A consulta de enfermagem no contexto da prática de enfermagem. In: ASSOCIAÇÃO BRASILEIRA DE ENFERMAGEM. Comissão Permanente de Serviço. Organização da Assistência de Enfermagem - DOC I. Brasília: ABEn, 1991.

BAIALARDI, K. S. O estigma da hanseníase: relato de experiência em grupo com pessoas portadoras. Hansen Int., v. 32, n. 1, p. 27-36, 2007. 
BOTI, N. C. L.; AQUINO, K. A. A via sacra da hanseníase de Veganin. Rev Bras Enferm, Brasília, v. 61, n. esp, p. 676-681, 2008.

BORENSTEIN, M. S. et al. Hanseníase: estigma e preconceito vivenciados por pacientes institucionalizados em Santa Catarina (1940-1960). Revista Brasileira de Enfermagem, v. 61, p. 708-712, 2008.

BRASIL. Ministério da Saúde. Secretaria de Vigilância em Saúde. Departamento de Vigilância Epidemiológica. Autocuidado em Hanseníase, Face, Mãos e Pés. Brasília: Ministério da Saúde, 2010b (. Série F. Comunicação e Educação em Saúde).

- Ministério da Saúde. Secretaria de Vigilância em Saúde. Departamento de Vigilância Epidemiológica. Programa Nacional de Eliminação da Hanseníase. Plano Nacional de Eliminação da Hanseníase em nivel municipal 2006-2010. Brasília: Ministério da Saúde, 2006.

CASOS de Hanseníase caem 15\% em um ano. O Estado de S. Paulo, São Paulo, 27 jan. 2012. Disponível em: <http://www.ceads.org.br/noticia_pag.php?id_conteudo=38>. Acesso em: 4 abr.2012.

CAVALCANTI, D. R. M. O surgimento do conceito "corpo": implicaçôes da modernidade e do individualismo. CAOS - Revista Eletrônica de Ciências Sociais, n. 9, p. 53-60, 2005. Disponível em: <http://www.cchla.ufpb.br/caos/diegorocha.pdf>. Acesso em: 22 abr. 2012. CHOMPRÉ, R. R. Autocuidado: necessidade ou responsabilidade? Rev. Baiana Enfermagem. Salvador, v. 7, n. 1/2, p. 153-61, 1994. CLARO, L. B. L. Hanseníase: representações sobre a doença. Rio de Janeiro: Fiocruz, 1995.

EIDT, L. M. Breve história da hanseníase: sua expansão do mundo para as Américas, o Brasil e o Rio Grande do Sul e sua trajetória na saúde pública brasileira. Saúde e Sociedade, São Paulo, v. 13, n. 2, 2004.

FERREIRA, F. R. A produção de sentidos sobre a imagem do corpo. Interface, Botucatu, v.12, n. 26, jul./set. 2008.

FOUCAULT, M. Microfísica do poder. 24. ed. Rio de Janeiro: Graal, 2007.

FELDENKRAIS, M. Consciência pelo movimento. 9. ed. São Paulo: Summus, 1977.

GAZZINELLI, M. F. et al. Educação em saúde: conhecimentos, representações sociais e experiências da doença. Cad. Saúde Pública, Rio de Janeiro, v. 21, n. 1, jan./fev. 2005.

GOFFMAN. E. Estigma: notas sobre a manipulação da identidade deteriorada. 4. ed. Rio de Janeiro: Guanabara Koogan, 1988.

HERZLICH, C. A Problemática da Representação Social e sua utilidade no campo da doença. Physis: Rev. Saúde Coletiva, Rio de Janeiro, v.15 (supl.), p. 57-70, 2005. 
LANGDON, E. J. A doença como experiência: a construção da doença e seu desafio para a prática médica. In: CONFERÊNCIA 30 ANOS XINGU. São Paulo: Escola Paulista de Medicina, 1995. Disponível em: <http://www.cfh.ufsc.br/ nessi/A\%20Doenca\%20 como\%20Experiencia.htm\#_ftn1>. Acesso em: 9 abr. 2012.

LE BRETON, D. A sociologia do corpo. Petrópolis: Vozes, 2006.

LELOUP, J. Y. O corpo e seus símbolos: uma antropologia essencial. Petrópolis: Vozes, 1998. LOURO, G. L. Pedagogias da sexualidade. In: (Org.). O corpo educado: pedagogias da sexualidade. 2. ed. Belo Horizonte: Autêntica, 2007, p. 9-34.

LOWEN, A. O corpo traído. 3. ed. São Paulo: Summus, 1979.

MACÁRIO, D. P. P. Desenho da figura humana de pessoas afetadas pela hanseníase. 2007. 135f. Dissertação (Mestrado em Ciências) - Programa de Pós-Graduação em Ciências, Coordenadoria de Controle de Doenças, Secretaria Municipal de São Paulo, São Paulo, 2007. MACHOVER, K. O traçado da figura humana: um método para o estudo da personalidade. In: Anderson, H. H.; Anderson, G. L. (Orgs.). Técnicas projetivas do diagnóstico psicológico. São Paulo: Mestre Jou, 1967, p. 345-369.

MAIA, A. R. C. R. Competência do individuo hipertenso para o auto-cuidado à saúde. 1991. 121 f. Dissertação (Mestrado em Enfermagem) - Universidade Federal de Santa Catarina, Florianópolis.

OPROMOLLA, D. V. A. Noçôes de hansenologia. Bauru: Centro de Estudos "Dr. Reynaldo Quagliato", 2000.

PINTO, P. G. H. R. O estigma do pecado: a lepra durante a Idade Média. Physis: Revista de Saúde Coletiva, v. 5, n. 1, p. 131-144, 1995.

SANTAELLA, L. Corpo e comunicação: sintoma da cultura. São Paulo: Paulus, 2004.

SANTOS, V. L. C. G.; SAWAIA, B. B. A bolsa na mediação do "estar ostomizado" - "estar profissional": análise de uma estratégia pedagógica. Rev. Latino-Am. Enfermagem, v. 8, n. 3, p. 40-50, 2000.

SILVA, A. M. Elementos para compreender a modernidade do corpo numa sociedade racional. Cadernos Cedes, ano 19, n. 48, p. 7-28, 1999.

SILVA, M. F.; SILVA, M. J. P. A auto-estima de pacientes ambulatoriais com queimaduras. Revista Baiana de Enferm. Salvador, v. 3, n. 17, p. 75-84, 2002.

SILVEIRA, E. L. da. Corpos silenciados em busca de identidade: espelhos que refletem a falta. Revista Eletrônica de Humanidades do Curso de Ciências Sociais da UNIFAP, Macapá, n. 5, p. 29-40, dez. 2012.

TAVARES, M. C. C. Imagem corporal: conceito e desenvolvimento. São Paulo: Manole, 2003. 
TRONCA, Í. As máscaras do medo: lepra e aids. São Paulo: EdUnicamp, 2000.

VAN KOLCK. Testes projetivos gráficos no diagnóstico psicológico. In: RAPPAPORT, C. R. (Coord.). Temas básicos de psicologia. v. 5., 6. ed. São Paulo: EPU, 1984.

VASCONCELOS, E. M. Educação popular nos serviços de saúde. São Paulo: Hucitec, 1989.

\section{Nota}

${ }^{1}$ T.V.G. Batista participou da concepção do projeto, pesquisa de campo, análise e interpretação dos dados, concepção e redação final do artigo. C.S.A. Vieira contribuiu na concepção e desenvolvimento do projeto e na redação final do artigo. M.A. Boccara de Paula orientou o projeto e participou da concepção e redação final do artigo. 


\section{Abstract}

\section{Body image in educational actions in self-care for people who had leprosy}

Physical impairment caused by leprosy are agreed in the National Plan for Leprosy Control and are considered a serious public health problem. In order to prevent the advance of disabilities, the Ministry of Health proposes educational actions in self-care. However, despite the emphatic importance of performing self-care, we observe non-adherence of patients to the program, which may be explained, among other reasons, by the destruction of their body image and the stigma arising from the social representations of the "leprous" body. Thus, we believe in the importance of increasing the technicist discourse in educational actions in self-care, considering body image as an important aspect in the treatment strategies of the disease. We aim to meet the body image of people who had leprosy and developed disabilities. For this, we applied the psychological test Human Figure Drawing (HFD), with emphasis on interpretive analysis of the hands and feet, the most affected by leprosy, in five women registered and monitored by the Self-Care Program in Leprosy, in a Regional Outpatient Clinic in the district of Vale do Paraíba Paulista. The test was conducted from March to December 2009. Results revealed the inclusion or disfigurement of hands and feet. There is a lack of integration between these regions and awareness, causing disruption of body image, which may result from both loss of cutaneous sensibility and the resulting deformity disease. It is inferred that this disruption of body image hinders adherence to self-care and socialization of these people, increasing the stigma of leprosy.

> Key words: leprosy; body image; social representation of the body; drawing of the human figure. 